\title{
Meriç Nehri Yatak İçi Kum Alımının Jeomorfolojik Değerlendirmesi
}

\section{Geomorphic Assessment of in-Channel Sand Excavation on the River Meriç, Turkey}

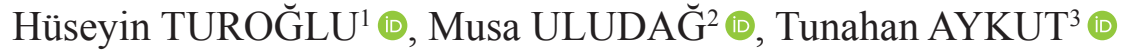 \\ ${ }^{1}$ İstanbul Üniversitesi, Edebiyat Fakültesi, İstanbul, Türkiye \\ ${ }^{2}$ Trakya Üniversitesi, Eğitim Fakültesi, Edirne, Türkiye \\ ${ }^{3}$ İstanbul Üniversitesi, Sosyal Bilimler Enstitüsü, İstanbul, Türkiye
}

ORCID: H.T. 0000-0003-0173-6995; M.U. 0000-0003-4395-3146; T.A. 0000-0003-0503-3859

\section{öz}

Hem taşkın önleme ve/veya zarar azaltma ve hem de ekonomik girdi sağlanması amacıyla, son 15 yıldır Meriç nehrinin Edirne bölümünde, yatak içi kum alımları yapılmaktadır. Kum alımları; Meriç Nehri'nin Edirne ilindeki 12 kilometrelik bölümde yer alan yatak içi kum birikimlerinin kazılması ile gerçekleştirilmektedir. Bu çalışmada, Meriç Nehri'nin Edirne ilindeki yatak içi kum alımlarının jeomorfolojik etkilerinin araştırılması ve sonuçlarının değerlendirmesi amaçlanmıştır. Meriç Nehrinin Edirne ilindeki 12 km'lik bölümü, 2009-2019 yılları için mercek altına alınmıştır. Meriç Nehrinin bu bölümdeki örgülü mecra patterni her yıl için haritalanmıştır. Yatak içi kum birikiminin yıllık değişimleri, akarsu yatak genişliği Coğrafi Bilgi Sistemleri ve Uzaktan Algılama teknolojileri kullanılarak belirlenmiştir. Akım rasatları, akarsu yatak morfolojisi değişim özellikleri birlikte ilişkilendirilmiştir. Akarsu kum madenciliğinin; Meriç nehrinin bu kısmında, hidrolojik ve jeomorfolojik doğal yapısının değişmesinde etkili bir rol oynadığı anlaşılmaktadır. Meriç Nehrinin doğal yatak formunun ve yatak kesit özelliklerinin değiştirilmesi; akarsu aşındırma ve biriktirme faaliyetlerinin değişmesine neden olmuştur. Değişikliklerin; beklenmedik jeomorfoloji problemleri için tetikleyici rol oynamasına neden olacağı öngörülmektedir. Akarsu kum madenciliği açısından beklenen ekonomik girdinin; fayda maliyet analizi perspektifinde yeniden değerlendirilmesi önerilmektedir. Tespit ve öngörüler, devam etmekte olan araştırmanın ilk sonuçlarını temsil etmektedir.

Anahtar kelimeler: Meriç Nehri, Edirne, Yatak İçi Kum Alımı

\section{ABSTRACT}

In-channel sand excavation has been implemented on the River Meriç flowing through Turkey for the last 15 years to prevent or mitigate floods and to generate income. Sand removal was carried out by digging in-riverbed sand deposits in the $12 \mathrm{~km}$ section of the river running alongside the city of Edirne. This study aimed to investigate the geomorphological effects of in-channel sand excavation on the River Meriç in the Edirne province and to evaluate the results. The $12 \mathrm{~km}$ section of the River Meriç in the Edirne province was examined between 2008 and 2019. The braided channel pattern of this part of the river was mapped for a one-year period. Annual variation characteristics were determined using GIS and RS. Flow observations and change characteristics in the river channel morphology were then correlated. Changing the natural river channel form and channel cross-sectional characteristics of the river has led to changes in river erosion and deposition. It is predicted that these changes will play a triggering role in causing unexpected fluvial geomorphology problems. We suggest that the expected economic input for river sand mining should be re-evaluated from the perspective of cost-benefit analysis.

Keywords: River Meriç, Edirne, In-channel Sand Excavation 


\section{EXTENDED ABSTRACT}

Since 2009, work for the prevention and mitigation of flash floods and flooding within and close to Edirne have been carried out by enlarging the channel of the River Meriç and performing in-channel sand excavation. Initially, in-channel sand excavation was begun both for commercial sand mining and to strengthen embankments along the riverbanks to manage flooding. Later, the in-channel sand excavation was largely transformed into river sand mining. The aim of this research was to investigate the effects of in-channel sand excavation on the hydrographic and geomorphological properties of the river's fluvial environment in the Edirne section.

The research was carried out on the $12 \mathrm{~km}$ section of the River Meriç within the Edirne province. For this section of the river, the annual change in size, shape, and spatial distribution of the sand islands was mapped using satellite images from 2009 to 2019 by means of a Geographic Information System and Remote Sensing. Regression analysis was applied to the trend of sand island change between 2009 and 2019. In addition, regression analysis of flow data observed at Kirişhane Flow Observation Station (General Directorate of State Hydraulic Works - "DSI" in Turkish) during the years 2009-2019 was performed.

River sand mining is carried out in the northern section close to Mehmet Muezzinoğlu Bridge. The sand islands' areal change in this section of the river was also compared with measurements of the southern section. Inferences were made by associating annual flow statistics and changes in the sand island area and location with current statistics and other data.

The first results of our research on the effects of in-channel sand excavation on the hydrographic and geomorphological properties of River Meriç are as follows.

In the $12 \mathrm{~km}$ section of the River Meriç within the borders of Edirne province, it was calculated that there are approximately 100 million tons of sand reserves. Morphologic changes in the sand islands of the river channel show that the intake of sand from the river channel has continued consistently throughout the last 10 years. River sand mining is being carried out in the river channel north of the Mehmet Müezzinoğlu Bridge with an extraction rate of sand at around 1 million m3 annually. Removal of sand from the river bed caused the size, shape and location of the sand islands in this part of the river to change constantly.

Due to the sand mining, the channel geometry, hydrodynamic, and fluvial geomorphology characteristics of the river were altered in this part of the Meriç. These changes have arisen from erosion and deposition in the Meriç because of the removal of sand in the river bed.

River bed cleaning and the construction of embankments along the riverbanks were made within the scope of a project initiated by the DSI between 15/12/2008 and 26/11/2010. This project caused an increase in the flood flow limits from $1000 \mathrm{~m}^{3} / \mathrm{sec}$ to $1400 \mathrm{~m}^{3} / \mathrm{sec}$ in the Edirne section of the River Meriç.

In principle, the sand islands in the stream occupy space within the bed, reducing the river bed cross-section of water flow and encouraging floods. It can be accepted that sand mining plays a preventive role against floods by reducing the accumulation of sand in the river bed. However, two issues are important here. One is that the balance between sand removal from the river bed and sand accumulation in the bed must be taken into consideration. River sand mining should be carried out with this balance in mind. The other issue is that care must be taken not to affect the river's hydrodynamic characteristics and groundwater circulation by excavating too deeply into the river bed.

The average flow values in humid and dry periods, calculated from observed data between 1986-2018 at Kirişhane Flow Observation Station $\left(26^{\circ} 34^{\prime} 20^{\prime \prime}\right.$ East, $41^{\circ} 38^{\prime} 50^{\prime \prime}$ North) (Figure 1) were analyzed. Linear regression analysis for the whole 32-year period shows that the flow trend in general is increasing.

The linear regression analysis (y) equation on the annual change of the sand islands shows a negative in sand accumulation in the sand mining part of the River Meriç for the 2009-2019 period. However, in the section after the Mehmet Muezzinoğlu Bridge, the regression equation is positive. In addition to the removal of sand from the river in-channel, the reason for this difference in the behaviour of the river is the important role played by the rock embankment built perpendicular to the flow direction in the river bed. The rock embankment made in the River Meriç channel has negatively affected the fluvial system and changed the erosion and deposition of the river. 


\section{GİRIŞ}

Edirne şehri (Şekil 1), geçmişten günümüze, sıklık ve şiddet özellikleri değişen sel ve taşkınlardan zarar görmektedir (Turoğlu ve Uludağ, 2010; Sezen, 2011; Turoğlu ve Uludağ, 2013; Turoğlu ve Uludağ, 2013; Erkal ve Topgül, 2015). Meriç nehri havzası bu bölümünün jeomorfolojik ve hidrografik özellikleri ile birlikte, çok büyük bölümü Bulgaristan'da kalan yukarı çığırına ait su yönetimi, Edirne'deki şehirsel yapılaşma ve şehrin içinden geçen Meriç nehri yatak özelliklerine yapılan müdahaleler; bu sel ve taşkınların sıklık ve şiddet özellikleri üzerinde belirleyici, yönlendirici rol oynamaktadır.

Meriç nehir yatağında biriken kumların alınması ve nehir yatağının derinleştirilmesinin, Edirne şehrinin sel ve taşkınlardan korunmasına önemli katkı sağlayacağı, aynı zamanda alınan bu kumların satışıyla önemli bir gelir elde edileceği düşüncesi (DSİ, 2006; Web 1; 2; 3; 4; 5; 6; 7); Meriç nehrinin Türkiye sınırları içinde kalan $12 \mathrm{~km}$ lik bölümünde kum alımları için bir gerekçe oluşturmuştur. Bu yaklaşım içinde, daha önceki yıllarda da olmasına rağmen, özellikle 2008 yılından sonra çok daha etkili olarak, Meriç nehri ile Arda nehrinin birleşiminden itibaren, Dr. Mehmet Müezzinoğlu köprüsüne kadar olan yatak içinde ticari amaçlı kum alımı yapılmaktadır. Dr. Mehmet Müezzinoğlu köprüsü ile Süvari köprüsü arasında ise temizleme amaçlı kum alımı yapılarak, yatak içinden alınan kum taşkın önleme amaçlı sedde oluşturulmasında kullanılmıştır (Şekil 1) (Foto 1; 2).

Bu çalışmada; Meriç nehrinin Edirne ilindeki, Türkiye sınırları içinde kalan yaklaşık 12 km’lik bölümünde, yatak içi kum alımlarına ait jeomorfolojik etkilerin araştırılması, ilk tespitlerin değerlendirmesi ve paylaşılması amaçlanmıştır.

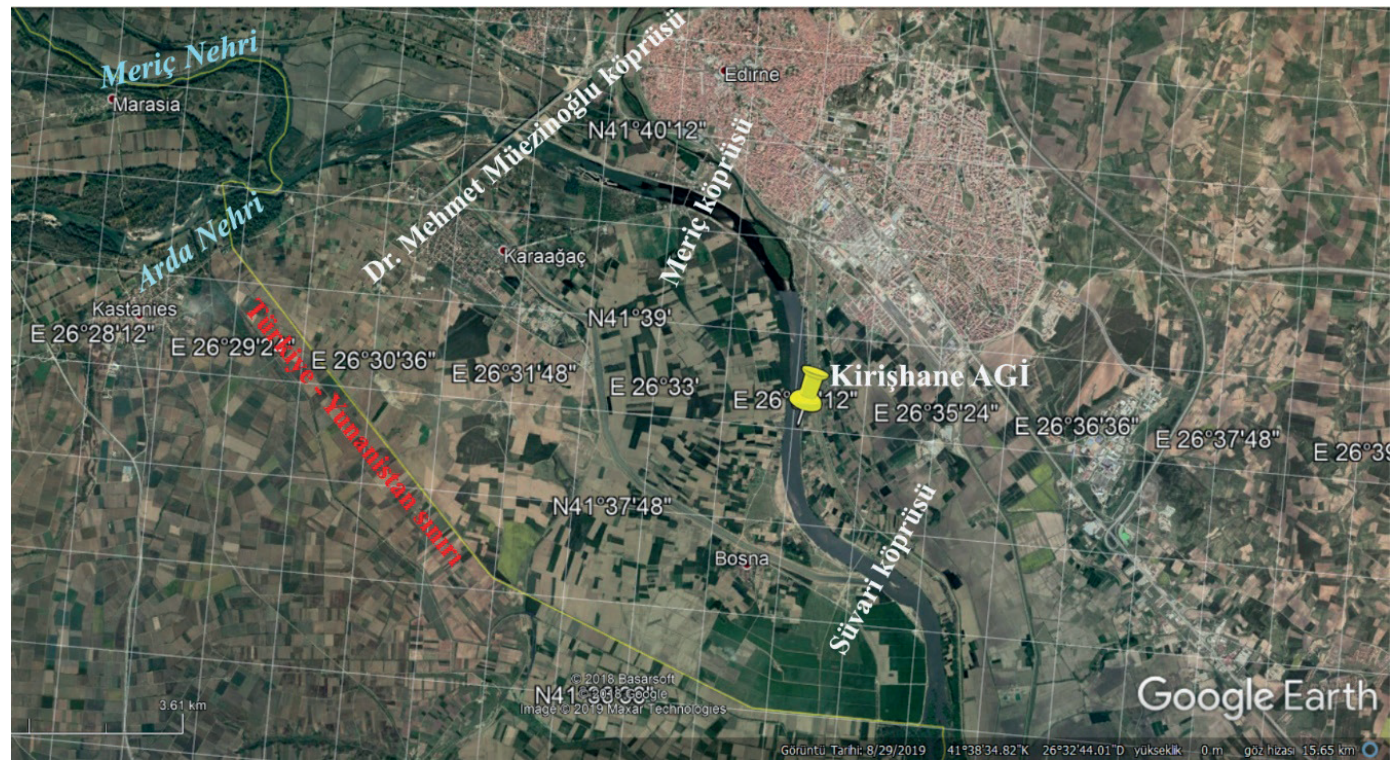

Şekil 1: Meriç Nehrinin Türkiye sınırları içindeki bölümü çalışıımıştır.

Figure 1: The part of the River Meriç within Turkey boundary has been studied.

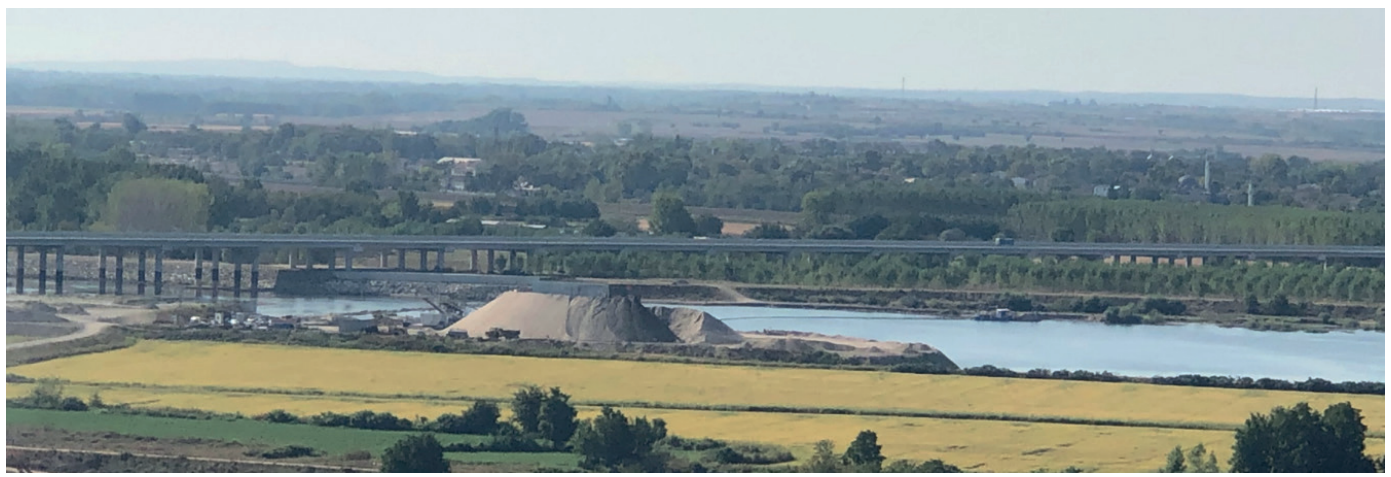

Foto 1: Dr. Mehmet Müezzinoğlu köprüsü ve Meriç nehri kum madenciliği deposu.

Photo 1: Dr. Mehmet Müezzinoğlu Bridge and sand mining warehouse on the banks of the River Meriç. 


\section{MATERYAL VE YÖNTEM}

Meriç nehri yatağından gerek ticari amaçlı ve gerekse temizleme amaçlı olarak yapılan kum alımları; Meriç nehrinin Türkiye sınırları içinde kalan, Edirne ilindeki 12 km'lik bölümü için, 2009-2019 yılları zaman aralığı itibarıyla mercek altına alınmıştır. Meriç nehrinin bu bölümdeki örgülü mecra yatak tipi; kum adalarının boyut, şekil ve dağılışları her yıl için uzaktan algilama (UZAL) ve coğrafi bilgi sistemleri (CBS) teknolojileri ile haritalanmıştır. Haritalama için her yılın Ağustos ayı hedeflenerek (bazı yıllarda görüntü eksikliği nedeni ile temmuz sonu ya da eylül başı) yüksek yersel çözünürlükteki Google Earth görüntüleri kullanılmıştır. Daha sonra, rasgele örnekleme yöntemi ile arazide, araştırma sonuçlarının doğruluk kontrolleri yapılmıştır.

Meriç nehrinin kum alımı yapılan bu bölümü için kum adası alan değişimi-yıllık ortalama akım değişimi ilişkisi araştırılmıştır. Bu analiz için; Devlet Su İşleri (DSI), 2009-2015 yıllarına ait Akım Gözlem Yıllıklarında (AGY) yer alan, 01. Meriç-Ergene Havzas1, D01A003 Meriç nehri, Kirişhane rasat istasyonu (26³4’20" Doğu - 4138'50" Kuzey, h: 30 m), yıllık ortalama akım verileri kullanılmıştır (DSİ, 2014, 2015, 2015a, 2016, 2016a, 2017, 2018, 2019). Kirişhane Akım Gözlem İstasyonu;
USGS tipi betonarme kule limnigrafı ile A-Çerçeve tipi çelik teleferikli olup, konum itibarıla inceleme yapılan $12 \mathrm{~km}$ 'lik bölümün akım yönündeki 10. kilometresinde (Süvari Köprüsüne 2 km kaynak yönünde) bulunmaktadır (Şekil 1).

\section{TESPITLER}

Meriç nehri yatağından kum alımlarının; sel taşkın önleme hedefli olmakla birlikte, uygulama olarak "yatak temizleme" ve "akarsu kum madenciliği" faaliyetlerinin gerçekleştirildiği anlaşılmaktadır. Akarsu kum madenciliğinin; Meriç nehrinin Arda nehri ile birleşiminden itibaren başlayıp, Dr. Mehmet Müezzinoğlu köprüsüne kadar olan bölümünde yapıldığı görülmektedir (Şekil 2, 3, 4A). Meriç nehri yatağında temizleme ve sedde oluşturma çalışmaları ise daha çok Dr. Mehmet Müezzinoğlu köprüsü ile Süvari köprüsü arasında (Şekil 4 B, C, D, E) yapıldı̆̆ 1 gözlenmiştir.

\section{1. Ön tespitler - I:}

Meriç Nehri’nin Edirne sınırları içindeki 12 km lik bölümde, yaklaşık 100 milyon ton civarında kum rezervi olduğu, bu rezervin yıllık 1 milyon 600 bin metreküp kum taşınması ile gerçekleştiği belirtilmektedir (Web 1, 2, 3, 4, 5). Meriç nehri

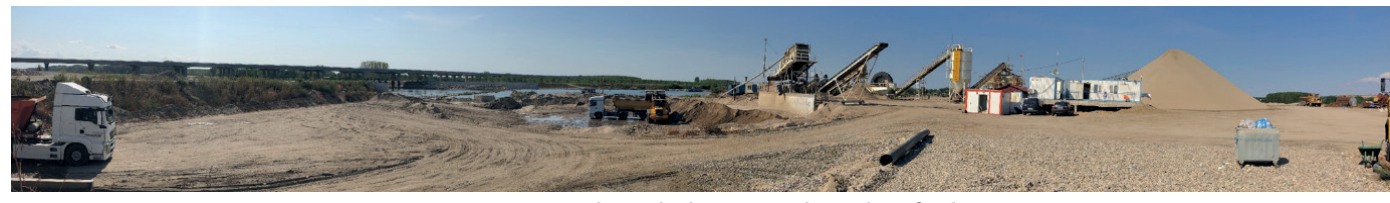

Foto 2: Meriç nehrinde kum madenciliği faaliyeti.

Photo 2: Sand mining activity in River Meriç.

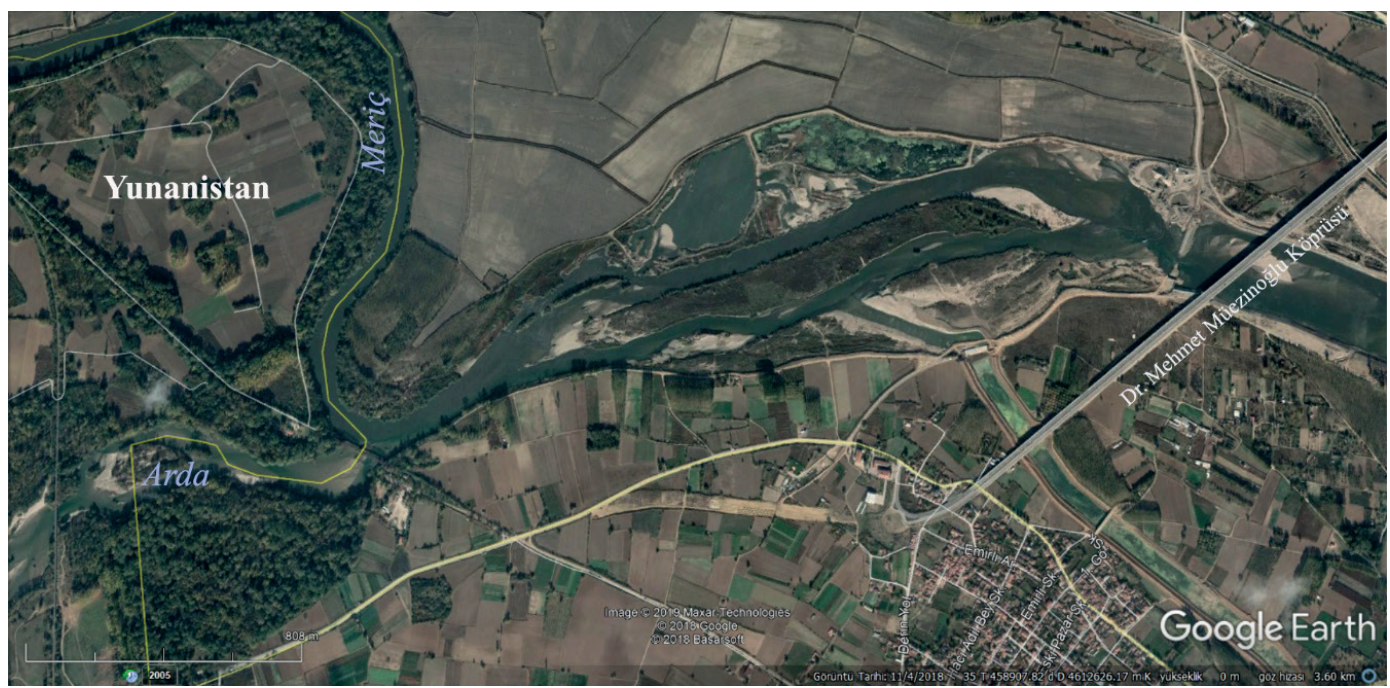

Şekil 2: Meriç nehrinde, akarsu kum madenciliği; Meriç-Arda nehirlerinin birleşimi ile Dr. Mehmet Müezzinoğlu köprüsü arasındaki bölümde yapılmaktadır. Figure 2: River sand mining in the River Meriç has been made between the merged section of Meriç - Arda rivers and Dr. Mehmet Müezzinoğlu Bridge. 
yatağından, kum alımlarının son 10 yılda etkili olarak sürdürüldüğü ve yıllık kum çıkarımının 1 milyon $\mathrm{m}^{3}$ seviyelerinde devam ettiği görülmektedir (Web 1, 2, 3, 4, 5, 6, 7) (Foto 1, 2).

Meriç nehrinde yapılan akarsu kum madenciliğinin sel ve taşkını önleme etkisi olduğu, yataktan ne kadar çok kum alınırsa, o oranda sel ve taşkın olasılığının azalacağı valilik ve diğer ilgili kurum yetkilileri tarafindan kabul edilmektedir (Web 1, 2, 5, 6, 7). Dip yükü olarak taşınan kum; yatak içinde, $10 \mathrm{~m}$ derinliğinde açılan çukur aracılığı ile tutulmakta, kil ve silt oranı çok düşük olan temiz ve iyi boylanmış kum, vakum aracılığı ile çekilmektedir.

\section{2. Ön tespitler - II:}

12 km'lik mesafe içinde, 2009-2019 döneminde, TemmuzAğustos aylarına ait görüntülerden yapılan belirleme sonuçları; kum adalarının alansal ve şekilsel olarak yıldan yıla değiştiğini (Şekil 3, 4 A, B, C, D, E), ayrıca kum birikim alanlarının lineer regresyon eğrisi de alansal azalma eğilimini (Şekil 5) göstermektedir. Son 10 yıllık dönem içinde hesaplanan en geniş kum adası alanı 2014 yılı ölçümüne aittir. Bu ölçüm tarihinden öncesine ait hesaplamalar artış eğilimi gösterirken,
2014 ölçümü sonrasında kum adası alanında istikrarlı bir azalma gerçekleşmiştir (Şekil 4, Şekil 5).

Yapılan müdahaleler sonucu, kabaca son 15 yıl içinde, Meriç nehrinin Türkiye sınırı içinde kalan bölümünde hem kanal geometrisi ve hem de kanal tipi açısından önemli değişiklikler olmuştur. Bu değişiklikler akarsuyun bu bölümündeki doğal hidrodinamiğini de değiştirmiştir. Bu sürece bağlı olarak; çarpma ve kayma yamaçları, kum birikimi ve aşınım sahaları, kum adaları ve banklarının şekilsel ve alansal özelliklerinin sürekli farklılaştığı tespit edilmiştir (Şekil 4 A, B, C, D, E),

\section{3. Ön tespitler - III:}

Meriç nehri yatağı içindeki kum adaları ve şeritlerinin temizlenip, nehrin akış kapasitesinin yükseltilerek Edirne şehri ve çevresinde afete dönüşen sel ve taşkınların önleneceği ön görülmüştür. $\mathrm{Bu}$ öngörü doğrultusunda; DSİ tarafından 15/12/2008-26/11/2010 yılları içinde uygulanan bir proje (DSİ, 2006) kapsamında, Meriç nehrinin Edirne şehrini tehdit eden 7,5 km'lik bölümünde yatak temizliği ve taşkın levelerinin yeniden düzenlenmesi gerçekleştirilmiştir. Bu çalışma ile Meriç nehrinin bu bölümünde, yatak taban genişliğini 170 m’ye, yatak derinliğini

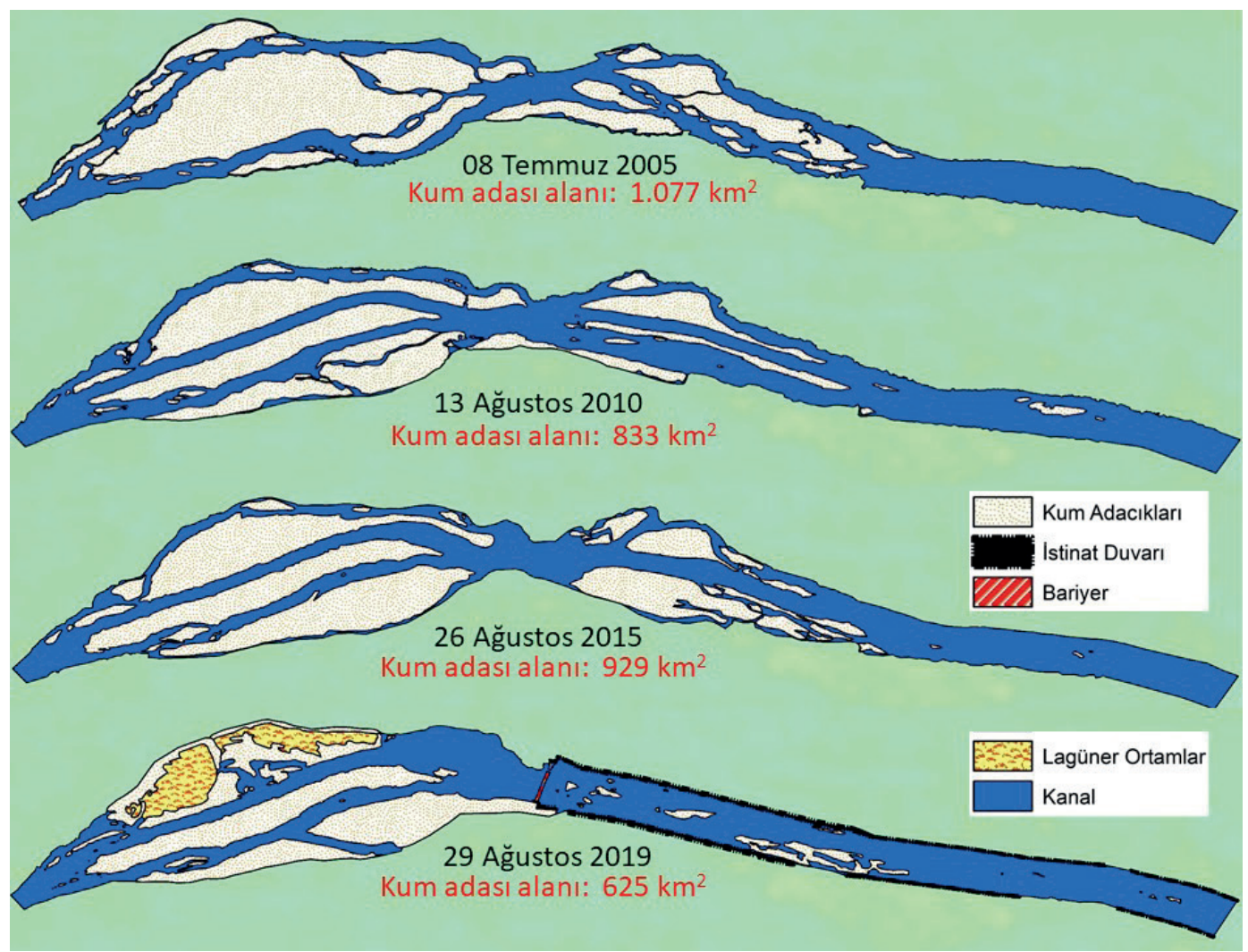

Şekil 3: Akarsu kum madenciliği nedeniyle Meriç nehri kanalındaki jeomorfolojik değişim.

Figure 3: Geomorphological change within River Meriç channel because of the river sand mining. 
5 m’ye ve yamaç eğimini de düzenleyerek genişliği 200 m’ye çıkartılmıştır. Önceleri taşkınlar için $1000 \mathrm{~m}^{3} / \mathrm{sn}$ 'lik akımlar yeterli olurken, Bu proje sonrasında, taşkın için sınır akımları $1400 \mathrm{~m}^{3}$ /sn'ye yükselmiştir. Afet niteliğinde meydana gelen son taşkın 07 Şubat 2012 tarihinde gerçekleşmiş olup, sonraki su seviyesi yükselmeleri bu taşkının seviyelerine ulaşmamıştır.

\section{Kirişhane AGİ (26³4'20” Doğu, 41³8'50” Kuzey) (Şekil 1)} 1986-2018 yıllarına ait 33 yıllık, nemli (ekim, kasım, aralık, ocak, şubat, mart ayları) ve kurak (nisan, mayıs, haziran, temmuz, ağustos, eylül ayları) dönemler için ortalama akım değerleri belirlenerek analiz edilmiştir (Şekil 6). Her üç dönem için lineer regresyon analizi; Meriç nehri Kirişhane akım gözlem istasyonu itibarıyla, akımın genel olarak artış eğilimi içinde olduğunu göstermektedir (Şekil 6).

\section{4. Ön tespitler - IV:}

Akarsuyun kum alımı yapılan bu bölgedeki 12 km'lik mesafesi; Dr. Müezzinoğlu köprüsünden itibaren kuzey ve güney olmak üzere iki bölüm olarak sınıflandırılabilir. Dr. Müezzinoğlu köprüsünden akarsuyun kaynak istikametindeki kuzey bölümü ile mansap istikametindeki güney bölümünde, yatak içi kum birikimlerinin yıllar içindeki alansal ve şekilsel değişimlerinin birbiri ile uyumlu olmadığı görülmektedir (Şekil 4, 7). Akarsu kum madenciliği amaçlı kum alımı; Dr.

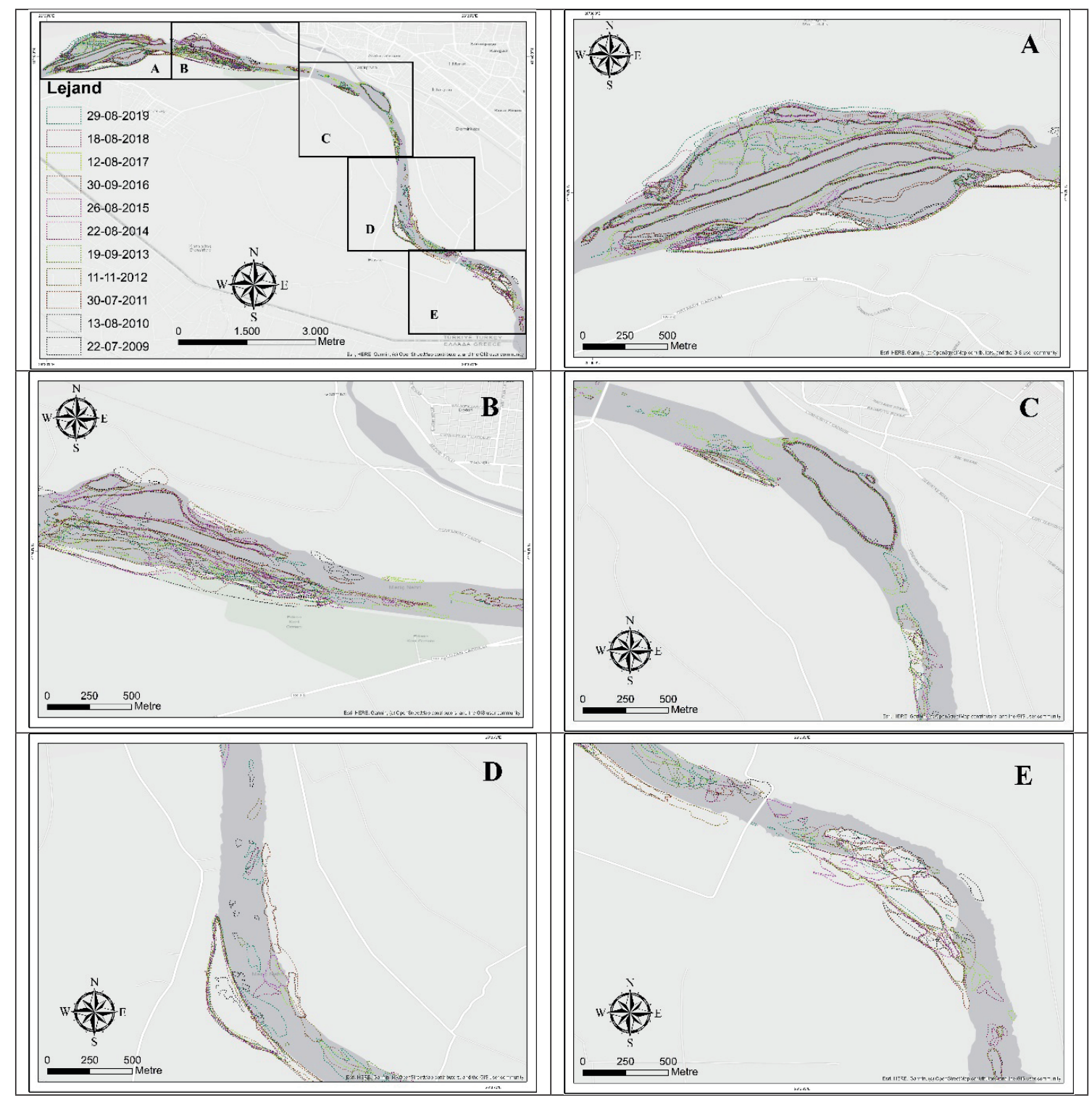

Şekil 4: 2009-2019 yılları arasında kanal içi kum kazısı yapılan Edirne'de Meriç nehri kanalının 12 km'lik bölümündeki kum adalarının alansal, şekilsel ve mekânsal değişimleri.

Figure 4: The areal, formal and spatial changes of sand islands within $12 \mathrm{~km}$ part of the River Meriç channel in Edirne, where made in-channel sand excavation between 2009-2019 years. 


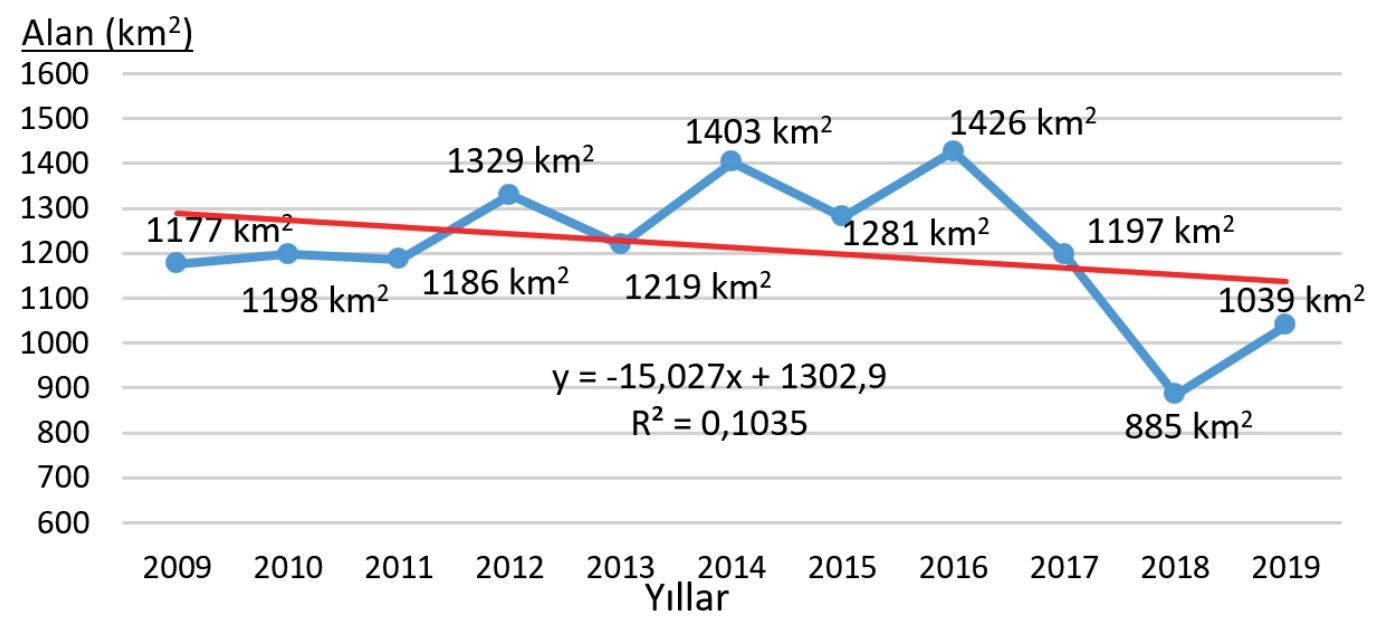

Şekil 5: Kanal içi kum kazılarının yapıldığı Meriç nehri kanalının 12 km'lik bölümünde 2009-2019 yılları arasında kum adası alansal değişim grafiği. Figure 5: The sand island areal change graph between 2009-2019 years in $12 \mathrm{~km}$ part of the River Meriç channel where made in-channel sand excavation.

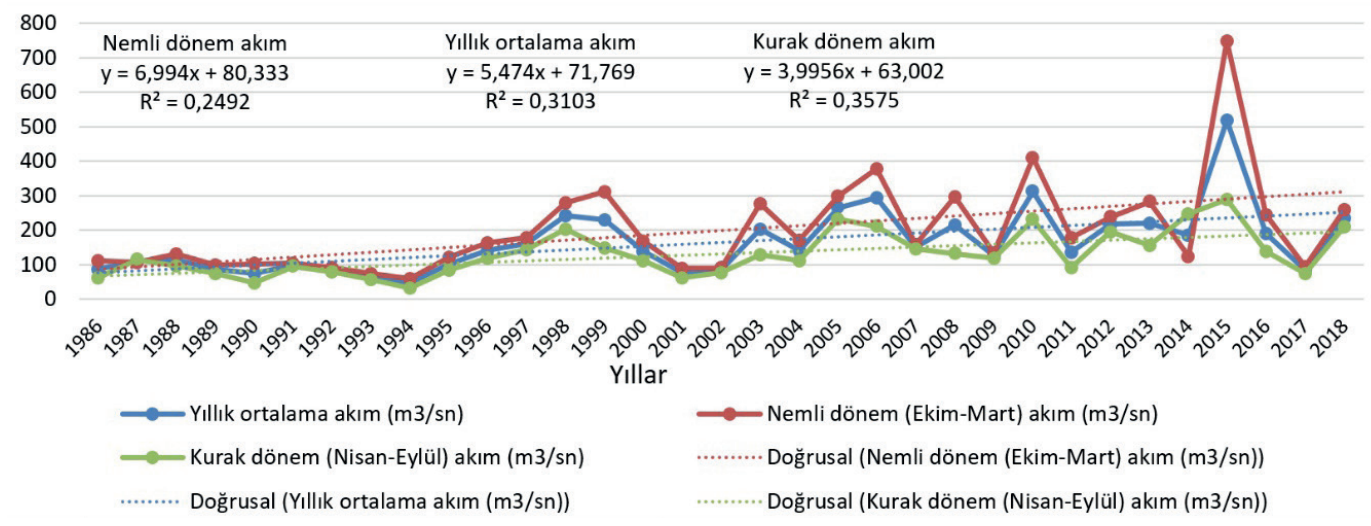

Şekil 6: 1986-2018 yıllarına ait yıllık, nemli ve kurak dönemler için ortalama akım rasatları lineer regresyon analizi.

Figure 6: Linear regression analysis of mean flow rates for annual, humid and arid periods from 1986 to 2018.

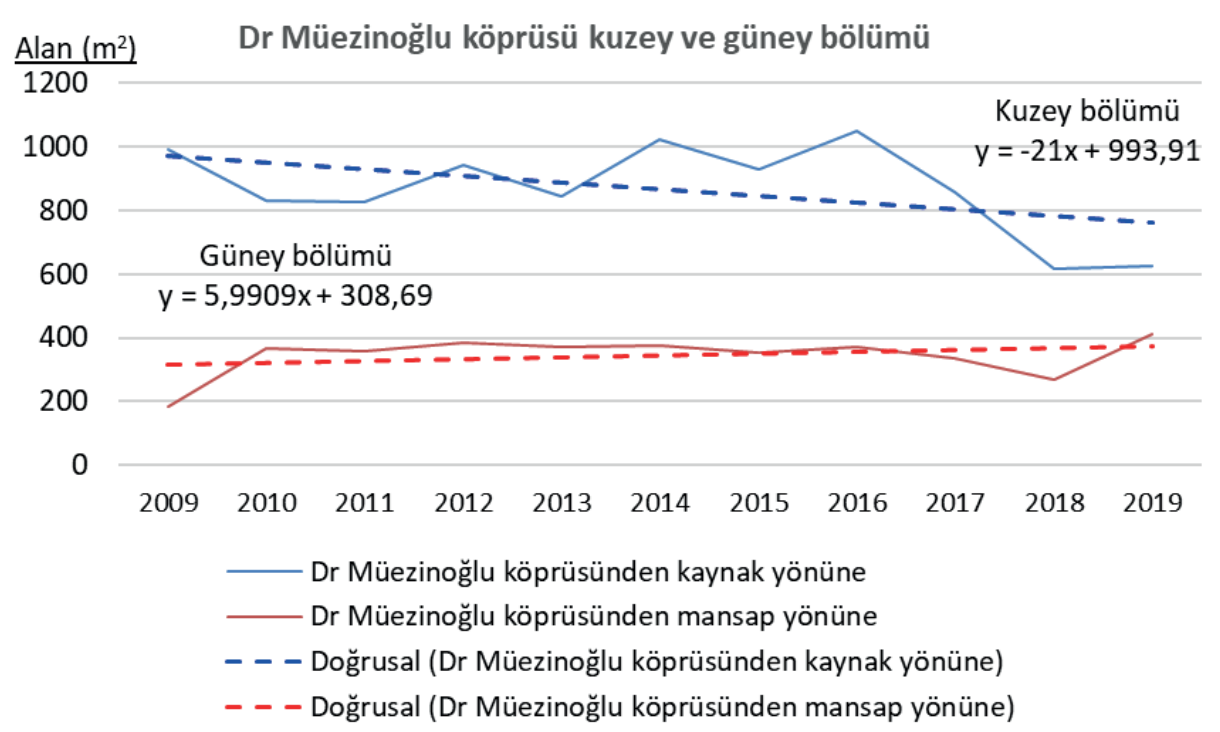

Şekil 7: Iki bölüm olarak 2009-2019 yılları arasında Mehmet Müezzinoğlu Köprüsü’nden Meriç nehrinin yukarı ve aşağı yönlerine doğru kum adalarının alansal değişim grafiği.

Figure 7: As two part, areal change graph of sand islands between 2009-2019 years from Mehmet Müezzinoğlu Bridge towards the upstream and downstream of River Meriç. 
Müezzinoğlu köprüsü ile kaynak istikametinde, Arda ile Meriç nehirlerinin birleşme bölgesi arasında (kuzey bölümü) yapılmaktadır (Şekil 2, 3). Meriç nehrinin bu bölümünde, yılın aynı dönemlerindeki kum adası alanlarının yıldan yıla değişim göstermesi, bu değişikliklerin 2009 yılından bu yana önce azalması ve daha sonra 2016'ya kadar küçük oynamalara rağmen artış göstermesi, 2016'dan sonra ise azalma eğilimi içinde olması dikkat çekmektedir (Şekil 7). 2009-2019 periyodu, yılın aynı dönemi kum adası alanı ölçümlerine ait regresyon denklemi (negatif y eşitliği); kum adası alanında belirgin bir azalma trendi göstermektedir (Şekil 7). Temizlik ve yatak düzenleme çalışmalarının yapıldığı, Dr. Müezzinoğlu köprüsü-Süvari köprüsü arasındaki bölümde (güney bölümü) ise; her yıl için hesaplanan kum adası alanlarında çok önemli değişiklik görülmemektedir (Şekil 7).

\section{5. Ön tespitler - V:}

Kum, çakıl, vb. sedimentlerin Meriç nehri yatağından aşağıya taşınmasına ve nehir yatağının dolmasına engel olmak amacıyla; Dr. Müezzinoğlu köprüsünden $150 \mathrm{~m}$ kaynak tarafinda, akarsu yatağının enlemesine, akışa dik "kaya dolgu set" yapılmıştır (Şekil 2) (Foto 3). Meriç Nehri yatağında yapılan kaya dolgu seti; akarsuyun bu bölümünde, onun hidrodinamiğini bozarak doğal aşındırma, taşıma ve biriktirme faaliyetinin değişmesine neden olmuştur. $\mathrm{Bu}$ değişikliğin etkilerinden biri de kuzey bölümünde meydana gelen ve gelişen göllenmelerdir. Önceki yılların aksine, 29 Ağustos 2019 tarihli ölçümde belirlenen göllenme (Şekil 3); Meriç nehrinin bu bölümüne yapılan müdahalenin, flüviyal sistem üzerindeki etkisinin doğal bir sonucudur. Yapılan kaya dolgu set; akım üzerinde engelleyici

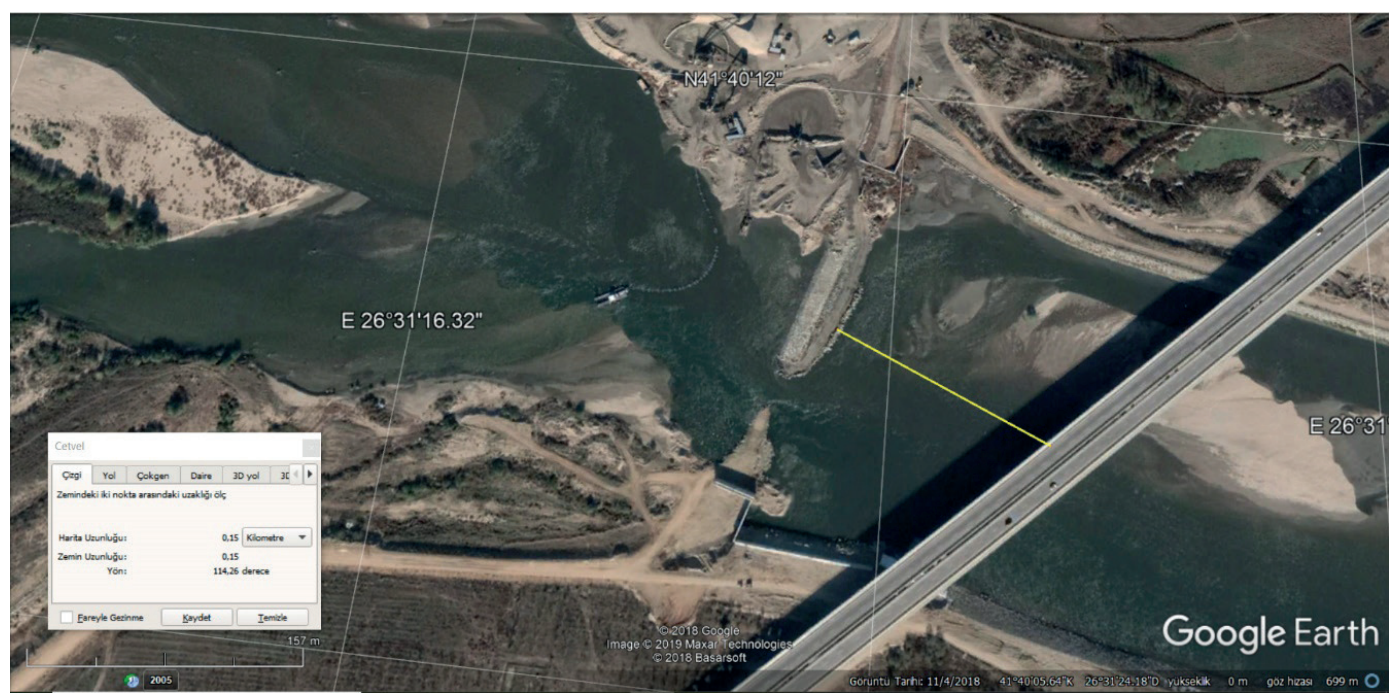

Şekil 8: Dr. Mehmet Müezzinoğlu köprüsü ve kanalda kum birikimini teşvik eden kaya dolgu seti. Bu set, Meriç nehrinin bu bölgedeki doğal erozyon, ulaşım ve birikim süreçlerinde önemli bir rol oynamıştır.

Figure 8: Dr. Mehmet Müezzinoğlu Bridge, and rock embankment set that encourages sand accumulation in channel. This embankment played a crucial role in the natural erosion, transport and deposition processes of the River Meriç in this region.

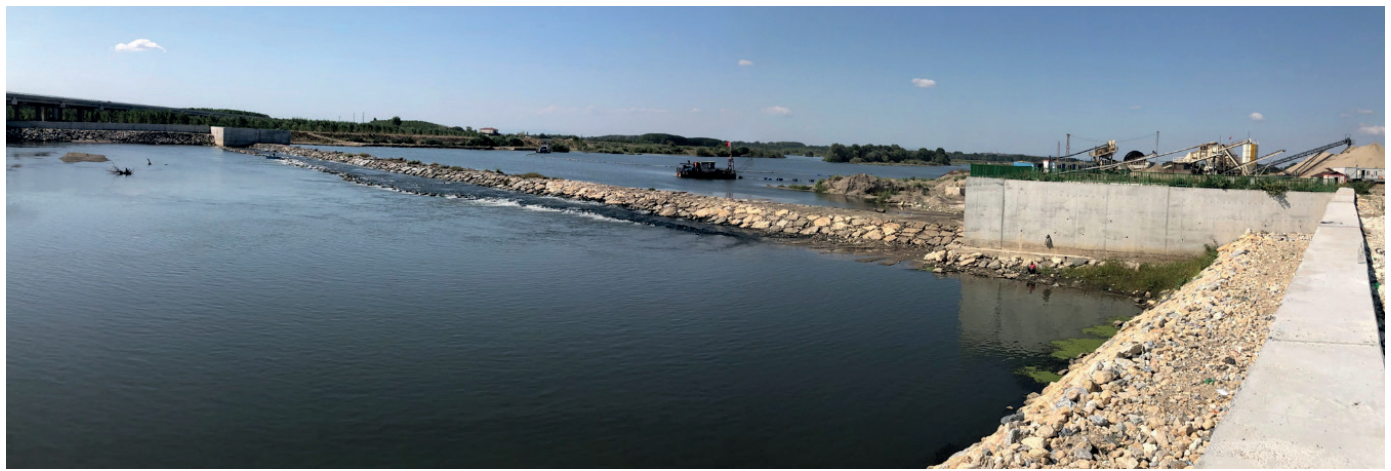

Foto 3: Kaya dolgu set, arkasında durgun bir su ortamı yaratarak kum birikmesine yol açan önemli bir rol oynamaktadır.

Photo 3: The rock embankment set has play an important role, leading to the accumulation of sand by creating a stagnant water environment behind it. 
rolü ile set gerisinde akım enerjisinin düşmesine, göllenmelere ve Meriç nehrinin bu bölümünde daha fazla kum birikmesine firsat vermiş̧ir. Kumun doğal taşınma düzenindeki değişim ve birikimin artması; akarsu kum madenciliği için hammadde zenginliği ve üretim miktarının artması anlamı taşımaktadır.

\section{6. Ön tespitler - VI:}

Meriç Nehri'nin Türkiye sınırları içinde kalan bölümünde yapılan yatak içi kum alımlarının ve buna bağlı gerçekleşen hidrodinamik değişikliklerin jeomorfolojik sonuçları; sadece bu bölüm ile sınırlı değildir ve olmayacaktır. Beklenen jeomorfolojik gelişmeler için üç bölüm sınıflandırılabilir. Bunlar; kaya dolgu setin de içinde bulunduğu kum madenciliği yapılan bölüm (kuzey bölümü), Kum madenciliği yapılan bölümden itibaren yukarı çığır istikameti (yurtdışında kalan bölüm) ve aşağı çı̆̆ır istikametidir (Türkiye-Yunanistan sınırı bölümü). Kaya dolgu set gerisinde göllenmeye bağlı birikim, kum madenciliği ve değişen yatak geometrisi; Meriç Nehri'nin kaynak yönündeki sınır ötesi yatağında, erozyonu arttırıcı flüviyal süreçler için tetikleyici olması beklenmelidir. Sediment yükündeki değişiklik; Türkiye-Yunanistan sınırını oluşturan Meriç Nehri'nin bu bölümünde de aşındırma ve biriktirme faaliyetlerin değişmesine neden olması beklenmelidir. Bu değişiklikler; sınır oluşturan Meriç nehrinin yatağında farklılaşmaların nedeni olacaktır. Meriç nehri yatağı flüviyal jeomorfoloji özelliklerindeki farklılaşma yavaş gelișen ancak zaman içinde hissedilecek olan jeomorfolojik bir süreçtir.

\section{7. Ön tespitler - VII:}

2009-2019 yılları itibarıyla Meriç nehrinin makaleye konu olan bölümündeki kum adası alansal değişimi ( $\mathrm{m}^{2}$ cinsinden) ile akarsuyun çalışılan bölümün mansap tarafındaki "Kirişhane Akım Gözlem İstasyonu akım rasatları, yıllık ortalama akım değerleri ( $\mathrm{m}^{3} / \mathrm{sn}$ cinsinden) esas alınarak karşılaştırılmıştır (Şekil 9). Meriç nehrinin Türkiye sınırları içindeki 12 km'lik mesafesi içinde kum adalarının 2009-2019 tarihleri için alansal değişimi Dr. Müezzinoğlu Köprüsü sınır olmak üzere iki bölüm olarak Şekil 7'de gösterilmiştir. Şekil 9 incelendiğinde kum adalarının alansal değişimindeki trend 2016 verisine kadar genel olarak artış gösterirken daha sonra çok dikkat çekici şekilde bir azalma gerçekleşmiştir. Bu azalma, doğrusal eğilim yönünü de negatife çevirmiştir. Kum adalarının alansal azalması Şekil 7'deki verilere göre Meriç köprüsünün kuzeyindeki akarsu kum madenciliği ile ilişkilidir. Yıllık ortalama akım değerlerindeki düzensizliklere rağmen, doğrusal eğilim yönünün pozitif olması dikkat çekicidir. Bu eğilim değeri 2015 yılına ait sıra dışı yüksek akım verisinden kaynaklanmaktadır (Şekil 9). 10 yıllık (20092018 yılları) ortalama akım değeri 222,4 m³/sn iken, 2015 yılında $518,9 \mathrm{~m}^{3} / \mathrm{sn}$ kayıt edilmiştir. $\mathrm{Bu}$ akım değerinden sonraki en yüksek akım değeri 312,6 m³/sn, en düşük akım değeri 84,2 m³ sn dir. Sıra dış1 $518,9 \mathrm{~m}^{3} / \mathrm{sn}$ lik akım doğrusal eğilimin pozitif çıkmasına neden olmuştur. 2015 akım verisinin ortalamalar seviyesinde olması halinde doğrusal eğilim negatif çıkarak akım miktarlarında da azalmaya işaret etmektedir.

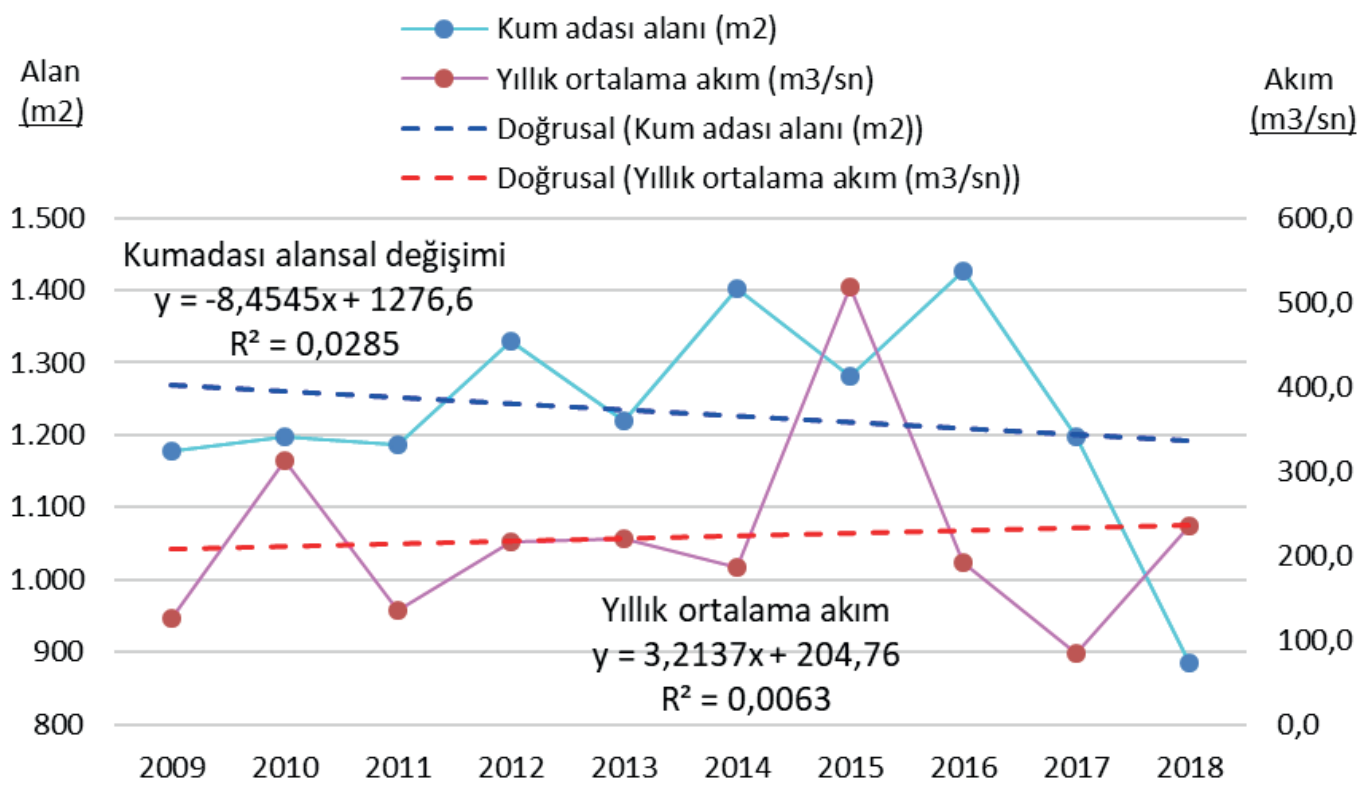

Şekil 9: 2009-2019 yılları için kum adalarının alansal değişiminin ve Kirişhane AGl yıllık ortalama debi verilerinin doğrusal regresyon analizi. Figure 9: Linear regression analysis of both the areal change of sand islands for 2009-2019 years and the Kirişhane AGl annual average flow rate data. 


\section{SONUÇ}

Meriç nehrinin Türkiye sınırları içinde kalan 12 km'lik bölümüne özellikle son 12 yıldan bu yana bir takım müdahaleler yapılmaktadır. $\mathrm{Bu}$ müdahalelerin temel gerekçesi; Edirne şehrinin sel ve taşkınlardan korunması amaçlı olduğu beyan edilmektedir. Yatak sutaşıma kapasitesinin arttırılmasına yönelik olarak, metin içinde güney bölüm olarak tanımlanan kısımda gerçekleştirilen; akarsu yatağından kum alımı ve taşkın seddeleri yapılmasının bu amaca hizmet ettiği kabul edilebilir. Böylece taşkına neden olan akım sınırı daha yüksek seviyeye çekilmiştir. Ancak bu çalışmaların; mansap istikametinde, akarsuyun çarpma ve kayma yamaçlarındaki aşındırma ve biriktirme doğal düzeninde farklılaşmalara neden olduğu belirlenmiştir. $\mathrm{Bu}$ durum; Meriç nehrinin sınır oluşturan bir nehir olması açısından dikkat edilmesi gereken önemli bir konudur.

Dr. Mehmet Müezzinoğlu köprüsünün $150 \mathrm{~m}$ kuzeyinde yapılan kaya dolgu seti Meriç nehrinin bu bölümünde akarsuyun doğal aşındırma, taşıma ve biriktirme düzenini tamamen değiştirmiştir. Bu değişiklik; sel taşkın önleme amacının dışında etkilerinin olacağ1 ve beklenmedik flüviyal jeomorfoloji ve çevre problemleri için tetikleyici rol oynayacağı kabul edilmektedir.

Metin içinde, kuzey bölümü olarak tanımlanan ve akarsu kum madenciliğinin yapıldığı bölümde, akarsu yatak formunda gerçekleştirilen değiş̧iklik ve ylllık 1 milyon $\mathrm{m}^{3}$ 'ten fazla üretimin yapıldığı akarsu kum madenciliği faaliyeti Meriç nehrinin sınır dışı bölümlerinde erozyonun ve sediment (kum) taşınmasının şiddetlenmesini teşvik etmesi beklenmelidir.

Prensip olarak akarsu yatağındaki kum adaları yatak içinde yer işgal ederek su akış kesitini düşürürler ve taşkınları teşvik ederler. Nehir kumu madenciliğinin nehir yatağında kum birikimini azaltarak taşkınlar için önleyici bir rol oynadığı kabul edilebilir. Ancak, iki konu çok önemlidir. Bunlardan biri; Nehir yatağından kumun çıkarılması ile yatakta kum birikimi arasındaki denge mutlaka dikkate alınmalıdır. Nehir kumu madenciliği bu denge göz önüne alınarak yapılmalıdır. Diğeri, nehir yatağında derin kazılar yapılarak nehir hidrodinamik özelliklerini ve yeraltı suyu dolaşımını etkilememeye dikkat edilmelidir.

Hem sınır aşan ve hem de sınır oluşturan, stratejik öneme sahip bir akarsu olan Meriç nehri üzerinde yapılacak müdahalelerin flüviyal jeomorfoloji perspektifindeki gelişim ve sonuçlarının göz ardı edilmemesi önerilmektedir.
Hakem Değerlendirmesi: Dış bağımsız.

Çıkar Çatışması: Yazarlar çıkar çatışması bildirmemiştir.

Finansal Destek: Yazarlar bu çalışma için finansal destek almadığını beyan etmiştir

Peer-review: Externally peer-reviewed.

Conflict of Interest: The authors have no conflict of interest to declare.

Grant Support: The authors declared that this study has received no financial support.

\section{KAYNAKLAR}

DSİ, (2006). Meriç Nehri Taşkın Koruma İşleri İnşaatı Projesi, TürkiyeBulgaristan sınır ötesi işbirliği bölgesinde taşkın tahmini için kapasite geliştirilmesi ve taşkın kontrolü projesi (TR0602-15), Avrupa Birliği Türkiye Katılım öncesi mali yardım, TürkiyeBulgaristan sınır ötesi işbirliği 2006 yılı programı.

DSİ, (2014). Devlet Su İşleri, 2009 Akım Gözlem yılllğı, 01. MeriçErgene Havzas1, D01A003 Meriç nehri, Kirişhane rasat istasyonu, Ankara.

DSİ, (2015). Devlet Su İşleri, 2010 Akım Gözlem yılllğı, 01. MeriçErgene Havzas1, D01A003 Meriç nehri, Kirişhane rasat istasyonu, Ankara.

DSİ, (2015a). Devlet Su İşleri, 2011 Akım Gözlem yılllı̆̆, 01. MeriçErgene Havzas1, D01A003 Meriç nehri, Kirişhane rasat istasyonu, Ankara.

DSİ, (2016). Devlet Su İşleri, 2012 Akım Gözlem yılllğı, 01. MeriçErgene Havzas1, D01A003 Meriç nehri, Kirişhane rasat istasyonu, Ankara.

DSİ, (2016a). Devlet Su İşleri, 2013 Akım Gözlem yılllğı, 01. MeriçErgene Havzas1, D01A003 Meriç nehri, Kirişhane rasat istasyonu, Ankara.

DSİ, (2017). Devlet Su İşleri, 2014 Akım Gözlem yılllı̆ı, 01. MeriçErgene Havzas1, D01A003 Meriç nehri, Kirişhane rasat istasyonu, Ankara.

DSİ, (2018). Devlet Su İşleri, 2015 Akım Gözlem yılllğı, 01. MeriçErgene Havzas1, D01A003 Meriç nehri, Kirişhane rasat istasyonu, Ankara.

DSİ, (2019). Devlet Su İşleri Etüt Planlama ve Tahsisler Dairesi Baskanlığı, Rasatlar Şube Müdürlüğü, Ankara.

Erkal, T. ve Topgül, İ. (2015). Meriç Nehri'nin son 15 yıllık taşkınları ve korunma projeleri (floods of Meriç River occurred in the last fifteen years and protection projects). TÜCAUM VIII. Coğrafya Sетровуити. http://tucaum.ankara.edu.tr/wp-content/uploads/ sites/280/2015/08/semp8_18.pdf, 165-174.

Gholap, V. S. (2016). Impact of sand dredging and silt extraction activity on river and its characteristics: A review. International Journal of Engineering Sciences \& Research Technology. 5(3); 1-4.

Jose, M. K., Shantanu, K. Y. ve Venkatesh, B. (2014). A study of effect of sand mining on riverine environment. Hydrolics, Water Resources, Coastal and Environmental Engineering. 129, 13781386. 
Kori, E. \& Mathada, H. (2012). An assessment of environmental impact of sand and gravel mining in Nzhelele Valley, Limpopo province, South Africa. 3rd International Conference on Biology, Environment and Chemistry, IPCBEE, 46; 137-141.

Sezen, N. (2011). Meric River floods and Turkish-Bulgarian cooperations.

Turoğlu, H. \& Uludağ, M. (2010). Floods and Flashfloods in Edirne (Turkey). 10Th International Multiciplinary Scientific Geoconference SGEM 2010, Conference Proceedings Volume II, Section "Hydrology and Water Resources", 7-14, Albena, Bulgaria.

Turoğlu, H. \& Uludağ, M. (2012). From past to present: Flooding in Edirne and its vicinity (Turkey). 2nd International Balkan Annual Conference (IBAC 2012): The Balkans at a Crossroads; Evaluating Past, Reading Present, Imagining Future, Proceeding Book Volume 2, Pages: 137-148, Tirana, Albania.

Turoğlu, H. ve Uludağ, M. (2013). Arşiv verilerine dayalı ön değerlendirme: Edirne'de meydana gelen eski ve güncel taşkınlar. Prof. Dr. Asaf Koçman'a Armağan. Ege Üniversitesi Yayınları, Edebiyat Fakültesi Yayın no:180, sayfa: 161-172, Bornova.

\section{WEB}

Web 1. http://www.hurriyet.com.tr/gundem/edirne-valisi-dursun-sahinben-bu-kumu-gorunce-yiyecegim-geliyor-40030975

Web 2. https://www.haberler.com/meric-kumu-duali-torenle-yolacikarildi-7995527-haberi/

Web 3. https://www.haberturk.com/gundem/haber/1171295-edirnevalisi-bu-kumu-gorunce-yiyecegim-geliyor

Web 4. https://www.turkiyegazetesi.com.tr/gundem/333999.aspx

Web 5. https://www.sondakika.com/haber/haber-edirne-meric-nehrinden-cikarilan-kumun-torenle-7996599/

Web 6. https://www.milligazete.com.tr/haber/997170/meric-kumualici-bekliyor

Web 7. http://www.edirneyenigun.com/haber/12845/meric-kumunayogun-talep.html 
